\title{
EFEITO DO CALCÁRIO E DO FÓSFORO NA PRODUTIVIDADE DE GRÃOS E SEUS COMPONENTES NOS CULTIVARES DE TRIGO ${ }^{(1)}$
}

\author{
JOSÉ GUILHERME DE FREITAS ${ }^{(2,6)}$, HEITOR CANTARELLA ${ }^{(3,6)}$, CARLOS EDUARDO \\ DE OLIVEIRA CAMARGO ${ }^{(2,6)}$, ANTONIO WILSON PENTEADO FERREIRA FILHO ${ }^{(2)}$, \\ JOÃO CARLOS FELICIO ${ }^{(2)}$, ARMANDO PETTINELLI JÚNIOR ${ }^{(4,5)} \&$ VALDIR JOSUÉ RAMOS $^{(5)}$
}

\begin{abstract}
RESUMO
O conhecimento da interação genótipos de trigo comum (Triticum aestivum L.) e fatores da produtividade de grãos (calcário, adubos, água e outros) é importante para escolha adequada de cultivares e insumos. O objetivo deste trabalho é verificar se existem diferenças entre genótipos de trigo quanto à resposta ao calcário e ao fósforo em relação à produtividade de grãos e seus componentes, ao comprimento da espiga e ao índice de colheita. Por nove anos, instalaram-se experimentos em um mesmo local, na Estação Experimental de Agronomia de Itararé. Efetuaram-se os experimentos sob condição de sequeiro e em sucessão ao pousio ou à soja. O delineamento estatístico foi o de blocos casualizados, em parcela subsubdividida, com quatro blocos. A parcela foi constituída por três doses de calcário $(0$, 6,5 e 13 t.ha-1 $)$; a subparcela, por três doses de fósforo $\left(0,30\right.$ e $90 \mathrm{~kg} \cdot \mathrm{ha}^{-1}$ de $\left.\mathrm{P}_{2} \mathrm{O}_{5}\right)$ e as subsubparcelas, por quatro genótipos ('IAC-5', 'IAC-24', 'IAC-60' e 'Anahuac'). A interação fósforo-calcário foi significativa, apresentando um efeito associativo positivo. O genótipo
\end{abstract}

\footnotetext{
(1) Trabalho realizado com apoio financeiro das Cooperativas do Vale do Paranapanema. Recebido para publicação em 24 de dezembro de 1997 e aprovado em 19 de agosto de 1998.

(2) Centro de Plantas Graníferas, Instituto Agronômico (IAC), Caixa Postal 28, 13001-970 Campinas (SP). E-mail: jfreitas@cec.iac.br

(3) Centro de Solos e Recursos Agroambientais, IAC.

(4) Estação Experimental de Agronomia de Tatuí , IAC.

(5) Estação Experimental de Agronomia de Itararé, IAC.

${ }^{(6)} \mathrm{Com}$ bolsa de produtividade em pesquisa do CNPq.
} 
IAC-60 mostrou-se mais produtivo em condições de solo ácido e deficiência de fósforo e mais responsivo à calagem e à adubação fosfatada; o 'IAC-5' foi mais produtivo e menos responsivo, e o 'IAC-24' e o 'Anahuac', menos produtivos e responsivos. O fósforo foi o fator que mais afetou a produtividade de grãos e seus componentes (número de espiguetas por espiga, número de grãos por espigueta e por espiga, massa da matéria seca de 100 grãos) e comprimento da espiga, ao passo que a calagem afetou mais o índice de colheita. O número de grãos por espiga foi o componente que melhor se relacionou com a produtividade de grãos.

Termos de indexação: trigo, genótipo, calcário, fósforo e componentes da produtividade de grãos.

\section{ABSTRACT \\ EFFECT OF LIME AND PHOSPHORUS APPLICATION ON WHEAT CULTIVARS' GRAIN YIELD AND ITS COMPONENTS}

The knowledge of the interactions among wheat genotypes (Triticum aestivum L.) and factors that affect grain yield (lime, fertilizer, water) is important for an adequate choice of cultivars and definition of a proper fertilization. The objective of this work is to study the variability of grain yield and yield components among wheat materials in response to lime and phosphorus application. The experiments were carried out annually, from 1987 to 1995, at the Itararé Experimental Station, Instituto Agronômico, Campinas, State of São Paulo, Brazil under dryland condition. A complete randomized block design in a split-split plot arrangement with 4 replications was used. The main plots contained three rates of lime $\left(0 ; 6.5\right.$, and 13 t.ha $\left.^{-1}\right)$, the split plots three rates of phosphorus $\left(0,30\right.$, and $90 \mathrm{~kg} \cdot \mathrm{ha}^{-1}$ of $\left.\mathrm{P}_{2} \mathrm{O}_{5}\right)$, and the split split plots four wheat genotypes ('IAC-5', 'IAC-24', 'IAC-60', and 'Anahuac'). The results showed that in acid and low-fertility conditions, the IAC-60 and IAC-5 genotypes surpassed the other materials in relation to grain yield, ear length, components of the grain yield and harvest index. The genotype IAC-60 was more responsive to lime and phosphorus. Grain yield, ear length, grain yield components and harvest index were more affected by P than by lime application. Grain yield correlated better with number of grains by ear than with other evaluated features. Considering grain yield, the genotype IAC-60 was more productive and more responsive, IAC-5 more productive but less responsive and IAC24 and Anahuac less productive. The use of genotypes tolerant to soil acidity and adapted to low fertility but responsive to lime and fertilizer can make feasible wheat cultivation in lowfertility soils with less investment.

Index terms: wheat, lime, phosphorus, grain yield, wheat yield components.

\section{INTRODUÇÃO}

A produtividade de grãos é uma característica controlada por um grande número de genes, sendo, portanto, herança quantitativa. Isso ocorre porque tal produtividade depende da interação de vários com- ponentes e do comprimento da espiga, os quais são controlados por fatores genéticos da planta e pelo ambiente. O número de espiguetas por espiga e de grãos por espigueta e por espiga e a massa da matéria seca de grãos afetam diretamente a produtividade de grãos (Evans et al., 1976). Por isso, as correlações 
entre a produtividade de grãos e seus componentes e mesmo entre estes podem ter valores significativos positivos ou negativos. Entre os fatores ambientais que mais afetam a produtividade de grãos do trigo, podem-se destacar os nutricionais e os climáticos. Entre os nutricionais, sobressaem os seguintes: o nitrogênio (Freitas et al., 1994, 1995); a calagem (Bataglia et al., 1985, Souza, 1996); o fósforo (Oliveira et al., 1984; Camargo \& Felício, 1987; Clark, 1990; Souza, 1996), e o boro (Silva et al., 1980, Silva \& Andrade, 1983).

A avaliação de componentes de produtividade e de outras características fenológicas das plantas de trigo, em função da resposta à aplicação de calcário e ou nutrientes, pode ajudar na seleção de genótipos mais responsivos e ou eficientes em programas de melhoramento genético. Para este estudo, selecionaram-se genótipos com características diferentes quanto à acidez do solo, altura e outras. Os cultivares IAC5, IAC-24 e IAC-60 são considerados tolerantes ao alumínio tóxico e à acidez do solo (Camargo \& Oliveira, 1981; Camargo \& Felicio, 1987) e de porte alto, semi-anão e médio respectivamente. Em trabalhos preliminares no IAC, com a competição de 200 genótipos de trigo, triticale e centeio em solos ácidos e pobres, observou-se que os genótipos de trigo IAC60 e IAC-5 ficaram entre os mais produtivos nas parcelas sem aplicação de calcário e de fósforo e mostraram-se responsivos a esses nutrientes. O IAC-24 teve produtividade de grãos intermediária e foi menos responsivo. O Anahuac foi pouco produtivo e apresentou uma amplitude de resposta menor do que os anteriores (Freitas \& Camargo, 1994, dados não publicados).

Os objetivos deste trabalho são: (1) estudar as respostas ao calcário e ao fósforo de quatro cultivares de trigo bem distintos quanto à nutrição e à acidez do solo; (2) identificar, entre os genótipos avaliados, os mais produtivos quanto à absorção e à utilização do fósforo e do calcário aplicados, em relação à produtividade de grãos e de seus componentes, ao comprimento da espiga e ao índice de colheita.

\section{MATERIAL E MÉTODOS}

Instalaram-se no mesmo local, em 1987-95, nove experimentos na Estação Experimental de Agronomia do IAC - Itararé - localizada na latitude de $24^{\circ}$ $15^{\prime} \mathrm{S}$, longitude de $49^{\circ} 15^{\prime} \mathrm{W}$ e altitude de 1.150 metros (Brasil, 1957). O solo é cambissolo álico, fase urutu, muito ácido e de baixa fertilidade. O clima é semitemperado (C.F.B.), com $674 \mathrm{~mm}$ de precipitação média, de março a setembro, e temperaturas anuais média, máxima e mínima de $17,0,21,0$ e $12,3^{\circ} \mathrm{C}$. Fizeram-se experimentos sob condição de sequeiro e em sucessão ao pousio (1987 a 1988) e à soja (1989 a 1995) em delineamento estatístico de blocos ao acaso no esquema parcela subsubdividida, com quatro repetições. A parcela foi constituída de três doses de calcário dolomítico $\left(0,6,5\right.$ e 13 t.ha ${ }^{-1}$, aplicadas em 1987 e reaplicadas nas mesmas quantidades em 1991, porque não se atingiram os valores recomendados de saturação por bases pretendidos. A subparcela foi formada por três doses de fósforo $\left(0,30\right.$ e $90 \mathrm{~kg} \cdot \mathrm{ha}^{-1} \mathrm{de}$ $\mathrm{P}_{2} \mathrm{O}_{5}$ ), reaplicadas no sulco de semeadura todos os anos, com os outros nutrientes. A fonte de fósforo foi o superfosfato simples. As subsubparcelas foram constituídas por quatro genótipos de trigo: IAC-5, IAC-24 e IAC-60, de origem nacional, de porte alto, semi-anão e médio respectivamente, e tolerantes ao alumínio, e o Anahuac, de origem mexicana, de porte semi-anão e sensível ao alumínio (Camargo \& Oliveira, 1981; Camargo \& Felicio, 1987).

A dose de $90 \mathrm{~kg} \cdot \mathrm{ha}^{-1}$ de $\mathrm{P}_{2} \mathrm{O}_{5}$ corresponde à máxima recomendada para os solos cultivados com trigo no Estado de São Paulo (Camargo et al., 1996).

As adubações nitrogenada e potássica foram constituídas de $60 \mathrm{~kg} \cdot \mathrm{ha}^{-1}$ de $\mathrm{N}$ (uréia) e $30 \mathrm{~kg} \cdot \mathrm{ha}^{-1}$ de $\mathrm{K}_{2} \mathrm{O}$ (cloreto de potássio), sendo $20 \mathrm{~kg} \cdot \mathrm{ha}^{-1}$ de $\mathrm{N}$ na semeadura, com os outros nutrientes, e $40 \mathrm{~kg} \cdot \mathrm{ha}^{-1} \mathrm{de}$ $\mathrm{N}$ em cobertura no estádio de alongamento (Z-30, 40 dias após a emergência das plântulas de trigo). Aplicaram-se os micronutrientes B e $\mathrm{Zn}$ nas doses de 550 e $1.100 \mathrm{~g}$. ha $^{-1}$, respectivamente, nas formas de bórax e sulfato de zinco. As subsubparcelas foram constituídas por sete linhas de $3 \mathrm{~m}$ de comprimento, espaça- 
das de 0,2 m, sendo a densidade de semeadura de oitenta sementes viáveis por metro linear. Durante os experimentos, as plantas de trigo foram pulverizadas com o fungicida propiconazole (p.a.) (Tilt) e as plantas daninhas controladas com a aplicação do herbicida 2-4-D. Os estandes inicial e final foram obtidos contando, ao acaso (estádios de terceira folha e de maturação dos grãos), o número de plantas e de espigas por metro linear respectivamente, no mesmo local da área útil de cada unidade experimental. Foram colhidas cinco linhas centrais para quantificar a produtividade de palha e de grãos e realizadas sete colheitas no período de 1987 a 1995, pois em 1990 e 1994 não houve produtividade de grãos em vista de geadas. Coletaram-se dez espigas ao acaso, por parcela, em 1987, 1988 e 1990, e avaliou-se o comprimento da espiga e os componentes da produtividade de grãos (número de espiguetas por espiga, de grãos por espigueta e por espiga, massa da matéria seca de cem grãos), de acordo com Camargo (1989). O índice de colheita foi obtido pela divisão da produtividade de grãos pela massa da parte aérea, para 1987 a 1989.

Efetuaram-se análises individuais e/ou conjuntas da variância dos dados com auxílio do programa de Sistema de Análise Estatística (SANEST) (Zonta et al. 1987). As conjuntas foram realizadas após a verificação da homogeneidade das variâncias dos erros (quadrado médio do resíduo) das subsubparcelas. A homogeneidade da variância dos resíduos das subsubparcelas foi calculada, dividindo-se os maiores erros das análises individuais pelos menores resíduos e multiplicando-se por 2. Como os valores encontrados foram menores ou iguais a 7 , foi possível realizar as análises conjuntas (Cochran \& Cox, 1957). Utilizou-se o teste de Tukey a 5\% para comparar as médias entre genótipos, pelas variâncias complexas calculadas dentro de cada dose de calcário e de fósforo, conforme Cochran \& Cox (1957). Correlações lineares simples (a $5 \%$ de probabilidade, pelo teste t) foram calculadas para estimar as relações entre produtividade de palha e de grãos, altura de planta, componentes da produtividade, comprimento da espiga, índice de colheita e estandes inicial e final.

\section{RESULTADOS E DISCUSSÃO}

Os valores de P-resina, $\mathrm{pH}$ e saturação por bases, na amostra inicial do solo, foram de $4 \mathrm{mg} \cdot \mathrm{dm}^{-3}$, 3,9 e 4\% respectivamente. Após a calagem e aplicação do fósforo, em 1987, esses valores aumentaram na parcela com a maior dose de calcário para $6 \mathrm{mg} \cdot \mathrm{dm}^{-3}$, 5,9 e $63 \%$ respectivamente. Em 1990, porém, o pH atingiu 4,5 e a saturação por bases, 37\%, abaixo dos esperados. Desse modo, reaplicaram-se as mesmas doses de calcário (0, 6,5 e 13 t.ha-1 $)$, mas, em 1992, a saturação por bases chegou apenas a 39\%. Isso pode ser devido à alta lixiviação nesse solo extremamente arenoso, causado pelo alto índice pluviométrico. Outro fator que pode ter influenciado foi a capacidade tampão do solo, em vista, sobretudo, do alto teor de matéria orgânica do solo $\left(88 \mathrm{~g} \cdot \mathrm{kg}^{-1}\right)$.

A análise estatística mostrou efeitos significativos a $5 \%$, pelo teste $\mathrm{F}$, para doses de calcário e de fósforo, para genótipos e para as interações entre tais fatores em relação à produtividade de grãos e seus componentes (número de espiguetas por espiga, de grãos por espigueta e por espiga, e massa da matéria seca de cem grãos), índice de colheita e comprimento da espiga. Dessa forma, foi possível fazer o desdobramento da interação tripla para observar as possíveis diferenças significativas entre os genótipos de trigo dentro de cada dose de calcário e cada dose de fósforo, utilizando-se o teste Tukey a 5\% para comparar as médias. Os efeitos associativos entre calagem, fósforo e genótipos foram mais importantes do que os efeitos individuais desses fatores (Quadros 1, 2 e 3). O fósforo, porém, foi o que mais afetou os resultados.

Nas interações entre as três doses de calcário com as três doses de fósforo aplicadas, o genótipo IAC-60 apresentou a maior produtividade média de grãos (Quadro 1). O 'IAC-5' também se destacou, porém com produtividade geralmente pouco inferior à do 'IAC-60'; desse modo, ambos se mostraram os mais produtivos nas condições de solo ácido e pobre, o que já era esperado, uma vez que o 'IAC-5' é um dos genitores do 'IAC-60'. 
Quadro 1. Produtividade de grãos (PG), comprimento da espiga (CE) e número de espiguetas por espiga(NEE) de genótipos de trigo, em função da aplicação de calcário e fósforo. Cálculos com base em sete colheitas individuais para PG e três para CE e NEE, de 1987 a 1990

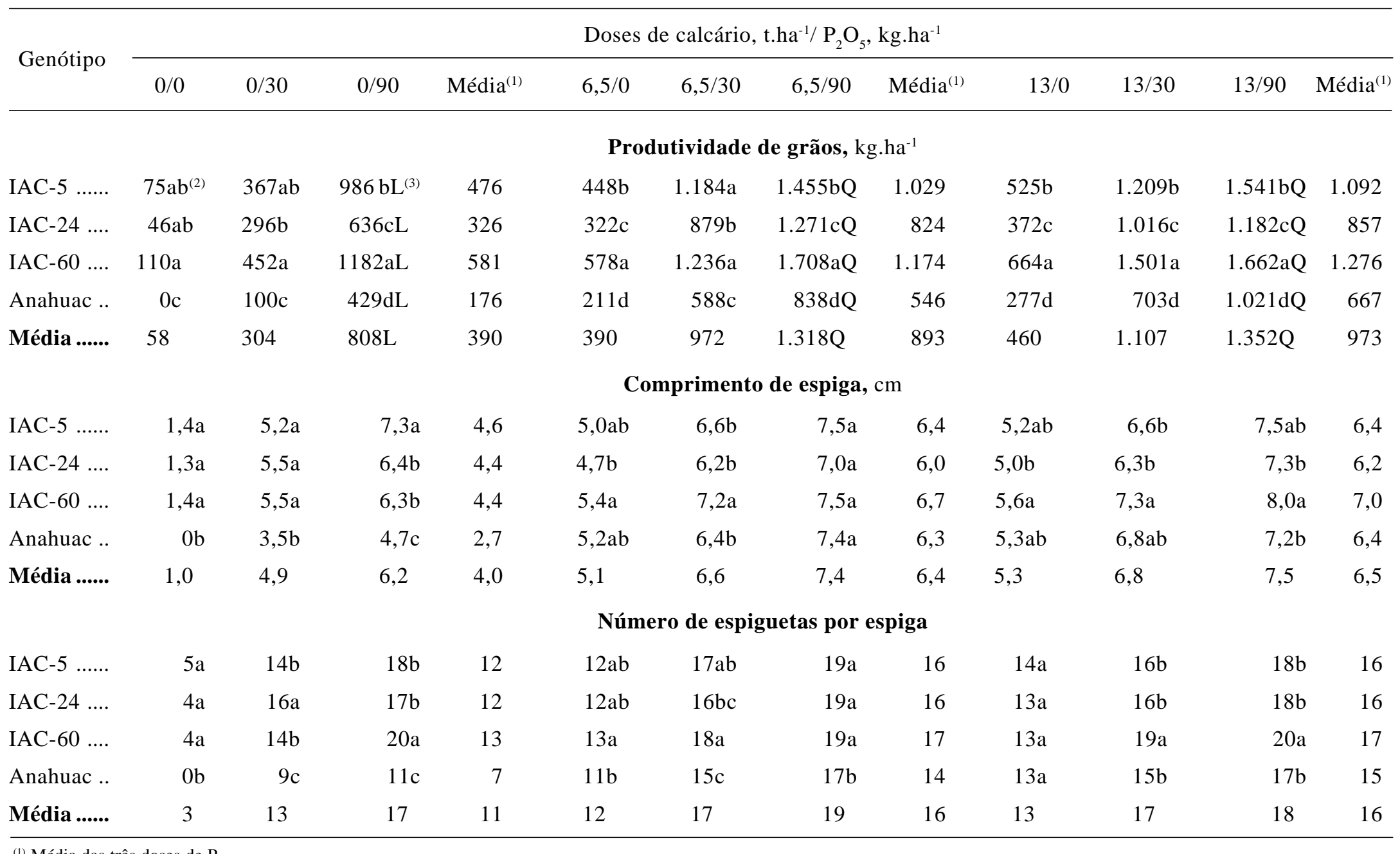

(1) Média das três doses de P.

(2) Médias seguidas pela mesma letra minúscula na coluna não diferem entre si, ao nível de 5\%, pelo teste de Tukey.

(3) Efeitos linear (L) e quadrático (Q) significativos (teste t, 5\%) para resposta a P de cada cultivar, para cada dose de calcário. 
Quadro 2. Número de grãos por espiga e por espigueta e massa da matéria seca de cem grãos de genótipos de trigo, em função da aplicação de calcário e fósforo. Cálculos com base em três colheitas individuais no período de 1987 a 1990

\begin{tabular}{|c|c|c|c|c|c|c|c|c|c|c|c|c|}
\hline \multirow{2}{*}{ Genótipo } & \multicolumn{12}{|c|}{ Doses de calcário, t.ha ${ }^{-1} / \mathrm{P}_{2} \mathrm{O}_{5}$, kg.ha ${ }^{-1}$} \\
\hline & $0 / 0$ & $0 / 30$ & $0 / 90$ & Média $^{(1)}$ & $6,5 / 0$ & $6,5 / 30$ & $6,5 / 90$ & Média $^{(1)}$ & $13 / 0$ & $13 / 30$ & $13 / 90 \mathrm{I}$ & Média $^{(1)}$ \\
\hline & \multicolumn{12}{|c|}{ Número de grãos por espiga } \\
\hline IAC-5 & $2 a^{(2)}$ & $11 \mathrm{bc}$ & $21 b$ & 11 & $12 \mathrm{~b}$ & $21 \mathrm{ab}$ & $26 \mathrm{bc}$ & 20 & $18 \mathrm{a}$ & $22 b$ & $30 \mathrm{a}$ & 23 \\
\hline IAC-24 & $2 \mathrm{a}$ & $14 \mathrm{ab}$ & $20 \mathrm{~b}$ & 12 & $13 b$ & $20 \mathrm{~b}$ & $27 b$ & 20 & $14 \mathrm{bc}$ & $20 b$ & $24 b$ & 19 \\
\hline IAC-60 & $2 \mathrm{a}$ & $15 \mathrm{a}$ & $26 \mathrm{a}$ & 14 & $17 \mathrm{a}$ & $24 \mathrm{a}$ & $31 \mathrm{a}$ & 24 & $16 \mathrm{ab}$ & $28 \mathrm{a}$ & $32 \mathrm{a}$ & 25 \\
\hline Anahuac & $0 \mathrm{~b}$ & $9 \mathrm{c}$ & $14 \mathrm{c}$ & 8 & $11 \mathrm{~b}$ & $20 \mathrm{~b}$ & $24 \mathrm{c}$ & 18 & $12 \mathrm{c}$ & 20 & $23 b$ & 18 \\
\hline \multirow[t]{2}{*}{ Média } & 2 & 12 & 20 & 11 & 13 & 21 & 27 & 21 & 15 & 23 & 27 & 21 \\
\hline & \multicolumn{12}{|c|}{ Número de grãos por espigueta } \\
\hline IAC-5 & $0,2 \mathrm{a}$ & $0,8 \mathrm{ab}$ & $1,2 \mathrm{a}$ & 0,7 & $1,1 b$ & $1,3 \mathrm{a}$ & $1,3 b$ & 1,2 & $1,4 \mathrm{a}$ & $1,4 \mathrm{ab}$ & $1,6 \mathrm{a}$ & 1,5 \\
\hline IAC-24 & $0,2 \mathrm{a}$ & $0,8 \mathrm{ab}$ & $1,1 \mathrm{a}$ & 0,7 & $1,1 b$ & $1,2 \mathrm{a}$ & $1,5 \mathrm{ab}$ & 1,3 & $1,2 \mathrm{a}$ & $1,2 b$ & $1,3 b$ & 1,2 \\
\hline IAC-60 & $0,1 \mathrm{a}$ & $1,1 \mathrm{a}$ & $1,3 \mathrm{a}$ & 0,8 & $1,3 \mathrm{a}$ & $1,3 \mathrm{a}$ & $1,6 \mathrm{a}$ & 1,4 & $1,2 \mathrm{a}$ & $1,5 \mathrm{a}$ & $1,6 \mathrm{a}$ & 1,4 \\
\hline Anahuac & $0 \mathrm{~b}$ & $0,7 \mathrm{~b}$ & $0,9 b$ & 0,5 & $0,9 b$ & $1,3 \mathrm{a}$ & $1,3 b$ & 1,2 & $0,9 b$ & $1,3 \mathrm{ab}$ & $1,3 b$ & 1,2 \\
\hline \multirow[t]{2}{*}{ Média } & 0,1 & 0,9 & 1,1 & 0,7 & 1,1 & 1,3 & 1,4 & 1,3 & 1,2 & 1,4 & 1,5 & 1,3 \\
\hline & \multicolumn{12}{|c|}{ Massa da matéria seca de cem grãos, g } \\
\hline IAC-5 & $1,13 \mathrm{a}$ & $2,99 \mathrm{~b}$ & $3,32 \mathrm{a}$ & 2,48 & $3,66 \mathrm{bc}$ & $4,13 \mathrm{ab}$ & $4,23 \mathrm{a}$ & 4,01 & $3,89 \mathrm{a}$ & $4,40 \mathrm{a}$ & $4,29 \mathrm{a}$ & 4,19 \\
\hline IAC-24 & $1,13 \mathrm{a}$ & $3,27 \mathrm{ab}$ & $3,53 \mathrm{a}$ & 2,64 & $3,53 \mathrm{c}$ & $3,83 \mathrm{c}$ & $3,90 \mathrm{~b}$ & 3,75 & $3,55 b$ & $3,97 \mathrm{~b}$ & $4,04 \mathrm{a}$ & 3,85 \\
\hline IAC-60 & $1,16 \mathrm{a}$ & $3,47 \mathrm{a}$ & $3,53 \mathrm{a}$ & 2,72 & $3,91 \mathrm{ab}$ & $4,43 \mathrm{a}$ & $4,13 \mathrm{ab}$ & 4,17 & $3,89 \mathrm{a}$ & $4,33 \mathrm{a}$ & $4,31 \mathrm{a}$ & 4,18 \\
\hline Anahuac & $0 \mathrm{~b}$ & $1,79 \mathrm{c}$ & $2,23 b$ & 1,34 & $3,98 \mathrm{a}$ & $3,98 \mathrm{c}$ & $4,03 \mathrm{ab}$ & 4,00 & $3,95 \mathrm{a}$ & $4,33 \mathrm{a}$ & $4,13 \mathrm{a}$ & 4,14 \\
\hline Média & 0,86 & 2,88 & 3,15 & 2,30 & 3,77 & 4,09 & 4,07 & 3,98 & 3,82 & 4,26 & 4,19 & 4,09 \\
\hline
\end{tabular}

(1) Média das três doses de P. (2) Médias seguidas pela mesma letra minúscula na coluna não diferem entre si, ao nível de 5\%, pelo teste de Tukey. 
Quadro 3. Índice de colheita dos genótipos de trigo, em função da aplicação de calcário e fósforo. Cálculos com base em sete colheitas individuais no período 1987-90

\begin{tabular}{|c|c|c|c|c|c|c|c|c|c|c|c|c|}
\hline \multirow{2}{*}{ Genótipo } & \multicolumn{12}{|c|}{ Doses de calcário, t.ha ${ }^{-1} / \mathrm{P}_{2} \mathrm{O}_{5}, \mathrm{~kg} \cdot \mathrm{ha}^{-1}$} \\
\hline & $0 / 0$ & $0 / 30$ & $0 / 90$ & Média $^{(1)}$ & $6,5 / 0$ & $6,5 / 30$ & $6,5 / 90$ & Média $^{(1)}$ & $13 / 0$ & $13 / 30$ & $13 / 90$ & Média $^{(1)}$ \\
\hline AC-5 & - & $0,369 \mathrm{a}^{(2)}$ & $0,453 \mathrm{a}$ & 0,284 & $0,360 \mathrm{a}$ & $0,380 \mathrm{ab}$ & $0,320 \mathrm{ab}$ & 0,353 & $0,447 \mathrm{a}$ & $0,352 \mathrm{ab}$ & $0,311 b$ & 0,370 \\
\hline IAC-60 & - & $0,323 a$ & $0,373 \mathrm{a}$ & 0,235 & $0,381 \mathrm{a}$ & $0,463 a$ & $0,392 \mathrm{a}$ & 0,412 & $0,439 a$ & $0,438 \mathrm{a}$ & $0,419 a$ & 0,432 \\
\hline Anahuac & - & $0,306 a$ & $0,239 b$ & 0,188 & $0,214 b$ & $0,303 b c$ & $0,266 \mathrm{~b}$ & 0,246 & $0,293 b$ & $0,290 b c$ & $0,280 \mathrm{~b}$ & 0,288 \\
\hline
\end{tabular}

(1) Média ds três doses de P. ${ }^{(2)}$ Médias seguidas pela mesma letra na coluna não diferem entre si, ao nível de 5\%, pelo teste de Tukey. 
Quadro 4. Coeficientes de correlação linear entre massa seca (kg.ha-1 ${ }^{-1}$ MSP) de plantas dos genótipos de trigo (G), produtividade de grãos (kg.ha ${ }^{-1}$,

PG), índice de colheita (IC), altura de planta (cm, AP), comprimento de espiga (cm, CE), número de espiguetas por espiga (NEE), número de grãos por espiga (NGE), e por espigueta (NGEP), massa seca de cem grãos (mg, MS100G), stand inicial (STIN) e stand final (STFI) em função de doses de calcário e de $\mathrm{P}_{2} \mathrm{O}_{5}$. Cálculos com base em sete colheitas individuais para MSP e IC e três para AP, CE, NEE, NGE, NGEP e MS100G de 1987 a 1990

\begin{tabular}{|c|c|c|c|c|c|c|c|c|c|c|c|}
\hline \multicolumn{2}{|c|}{ Genótipo } & \multicolumn{9}{|c|}{ Parâmetros da matriz de correlação } & STFI \\
\hline MSP & IAC-5 & 0,88 & 0,23 & 0,59 & 0,65 & 0,62 & 0,71 & 0,50 & 0,51 & 0,22 & 0,24 \\
\hline & IAC-24 & 0,80 & $\mathrm{~ns}$ & 0,69 & 0,69 & 0,65 & 0,80 & 0,70 & 0,47 & 0,34 & 0,40 \\
\hline & IAC-60 & 0,89 & $\mathrm{~ns}$ & 0,68 & 0,74 & 0,71 & 0,86 & 0,68 & 0,41 & 0,55 & 0,56 \\
\hline PG & IAC-5 & - & $\mathrm{ns}$ & 0,69 & 0,72 & 0,68 & 0,80 & 0,60 & 0,61 & 0,26 & 0,33 \\
\hline & IAC-24 & - & 0,38 & 0,70 & 0,69 & 0,60 & 0,87 & 0,76 & 0,40 & $\mathrm{~ns}$ & 0,38 \\
\hline & IAC-60 & - & 0,18 & 0,76 & 0,76 & 0,75 & 0,88 & 0,71 & 0,45 & 0,52 & 0,64 \\
\hline & Anahuac & - & 0,57 & 0,62 & 0,66 & 0,64 & 0,87 & 0,82 & 0,39 & $\mathrm{~ns}$ & 0,27 \\
\hline Média & & - & 0,31 & 0,63 & 0,70 & 0,68 & 0,86 & 0,71 & 0,46 & $\mathrm{~ns}$ & 0,33 \\
\hline & Anahuac & - & - & 0,43 & 0,45 & 0,43 & 0,50 & 0,53 & 0,41 & $\mathrm{~ns}$ & 0,27 \\
\hline Média & & - & - & 0,41 & 0,35 & 0,34 & 0,29 & 0,39 & 0,39 & ns & 0,27 \\
\hline $\mathbf{A P}$ & IAC-5 & - & - & - & 0,89 & 0,82 & 0,83 & 0,76 & 0,75 & $\mathrm{~ns}$ & 0,31 \\
\hline & IAC-24 & - & - & - & 0,91 & 0,89 & 0,78 & 0,73 & 0,79 & 0,34 & 0,77 \\
\hline & IAC-60 & - & - & - & 0,91 & 0,91 & 0,83 & 0,78 & 0,81 & 0,40 & 0,72 \\
\hline & Anahuac & - & - & - & 0,91 & 0,92 & 0,70 & 0,70 & 0,79 & 0,20 & 0,63 \\
\hline Média & & - & - & - & 0,81 & 0,81 & 0,71 & 0,68 & 0,72 & $\mathrm{~ns}$ & 0,43 \\
\hline CE & IAC-5 & - & - & - & - & 0,93 & 0,84 & 0,72 & 0,55 & $\mathrm{~ns}$ & 0,30 \\
\hline & IAC-24 & - & - & - & - & 0,96 & 0,82 & 0,75 & 0,84 & 0,29 & 0,74 \\
\hline
\end{tabular}


Parâmetros da matriz de correlação

\begin{tabular}{|c|c|c|c|c|c|c|c|c|c|c|c|}
\hline \multirow{2}{*}{\multicolumn{2}{|c|}{ Genótipo }} & \multirow[b]{2}{*}{ PG } & \multirow{2}{*}{ IC } & \multirow{2}{*}{$\mathrm{AP}$} & \multirow{2}{*}{$\mathrm{CE}$} & \multirow{2}{*}{ NEE } & \multirow[b]{2}{*}{ NGE } & \multirow{2}{*}{ NGEP } & \multirow[b]{2}{*}{ MS100G } & \multirow[b]{2}{*}{ STIN } & \multirow[b]{2}{*}{ STFI } \\
\hline & & & & & & & & & & & \\
\hline & IAC-60 & - & - & - & - & 0,97 & 0,89 & 0,82 & 0,81 & 0,47 & 0,75 \\
\hline Média & & - & - & - & - & 0,96 & 0,83 & 0,78 & 0,83 & $\mathrm{~ns}$ & 0,52 \\
\hline NEE & IAC-5 & - & - & - & - & - & 0,73 & 0,54 & 0,79 & 0,27 & 0,39 \\
\hline & IAC-24 & - & - & - & - & - & 0,74 & 0,64 & 0,86 & 0,39 & 0,77 \\
\hline & Anahuac & - & - & - & - & - & 0,77 & 0,77 & 0,82 & ns & 0,54 \\
\hline Média & & - & - & - & - & - & 0,78 & 0,69 & 0,81 & $\mathrm{~ns}$ & 0,54 \\
\hline NGE & IAC-5 & - & - & - & - & - & - & 0,89 & 0,55 & ns & ns \\
\hline & IAC-24 & - & - & - & - & - & - & 0,94 & 0,52 & $\mathrm{~ns}$ & 0,47 \\
\hline & IAC-60 & - & - & - & - & - & - & 0,90 & 0,58 & 0,47 & 0,65 \\
\hline & Anahuac & - & - & - & - & - & - & 0,96 & 0,47 & ns & 0,20 \\
\hline & IAC-60 & - & - & - & - & - & - & - & 0,68 & 0,34 & 0,63 \\
\hline & Anahuac & - & - & - & - & - & - & - & 0,53 & ns & 0,20 \\
\hline Média & & - & - & - & - & - & - & - & 0,58 & ns & 0,64 \\
\hline MS100G & IAC-5 & - & - & - & - & - & - & - & - & 0,33 & 0,52 \\
\hline & IAC-24 & - & - & - & - & - & - & - & - & 0,45 & 0,83 \\
\hline & IAC-60 & - & - & - & - & - & - & - & - & 0,30 & 0,62 \\
\hline & Anahuac & - & - & - & - & - & - & - & - & 0,25 & 0,74 \\
\hline Média & & - & - & - & - & - & - & - & - & 0,22 & 0,64 \\
\hline STIN & IAC-5 & - & - & - & - & - & - & - & - & - & 0,89 \\
\hline & IAC-24 & - & - & - & - & - & - & - & - & - & 0,58 \\
\hline & IAC-60 & - & - & - & - & - & - & - & - & - & 0,71 \\
\hline
\end{tabular}


As variedades IAC-24 e Anahuac apresentaram os menores valores da produtividade de grãos em relação à média geral, dentro de cada interação entre doses de calcário e de fósforo, revelando-se menos produtivas (Quadro 1). O comportamento do 'Anahuac' pode ser explicado pela sua extrema sensibilidade ao alumínio trocável e à baixa fertilidade do solo.

A resposta à calagem e à adubação fosfatada, com relação à produtividade de grãos, foi maior para o genótipo 'IAC-60' (Quadro 1).

$\mathrm{O}$ 'Anahuac' teve a menor resposta quantitativamente à calagem, o que pode ter ocorrido devido à tolerância à acidez do solo, em particular ao alumínio, dos outros cultivares. Isso ocorreu porquanto, apesar das calagens pesadas e da adição anual de fósforo, o solo permaneceu com teores relativamente baixos desses elementos. Oliveira et al. (1984) obtiveram valores menores da produtividade de grãos para os genótipos 'IAC-5' e 'Alondra-46', respectivamente, tolerante e moderadamente tolerante ao alumínio, para as mesmas condições de solo e clima. Os valores médios da produtividade de grãos do trigo obtidos por Camargo et al. (1984) e por Freitas et al. (1994, 1995) foram praticamente o dobro, para as demais regiões paulistas, em condições de sequeiro.

O genótipo de trigo 'IAC-60', de maneira geral, apresentou maior comprimento de espiga do que os demais e o Anahuac, na dose 0 de calcário, o menor (Quadro 1). Todos os genótipos responderam ao calcário e ao fósforo para o comprimento da espiga (Quadro 1), porém a resposta à calagem foi maior, até à dose de 6,5 t.ha-1, para todos os genótipos. As respostas dos genótipos de trigo ao fósforo seguiram um modelo quadrático, com um aumento substancial até a dose de $30 \mathrm{~kg}$.ha ${ }^{-1}$ de $\mathrm{P}_{2} \mathrm{O}_{5}$ e diminuíram em seguida, independentemente da dose de calcário. Mesmo não sendo considerado como componente da produtividade de grãos (Evans et al., 1976), o comprimento da espiga pode influenciá-lo bastante, especialmente em condições de acidez e fertilidade muito baixa do solo. Oliveira et al. (1984) encontraram valores muito próximos desses para o 'IAC-5', embora o coeficiente de variação e a amplitude mínima significativa fossem bem maiores do que obtidos neste trabalho.
Os cultivares de trigo IAC-5, IAC-24 e IAC60 não diferiram entre si com relação ao número de espiguetas por espiga, quando não se aplicaram calcário e fósforo (Quadro 1). Houve um aumento maior no número de espiguetas por espiga com o aumento das doses de calcário e de fósforo até 6,5 e $30 \mathrm{~kg} \cdot \mathrm{ha}^{-1}$. Após essas doses, os aumentos foram menores, talvez porque outras limitações da fertilidade do solo passaram a ser mais acentuadas (Quadro 1). O cultivar Anahuac, também para essa característica, mostrou valores inferiores aos demais e muito próximos aos obtidos por Oliveira et al. (1984), para o mesmo solo e clima, e inferiores aos obtidos por Camargo et al. (1984), que utilizaram plantas individuais em população segregante, enquanto neste trabalho estudaram-se linhas puras (cultivares).

O genótipo 'IAC-60', de maneira geral, apresentou o maior número de grãos por espiga (Quadro 2). As respostas ao fósforo e ao calcário para essa característica, de maneira geral, foram maiores para o mesmo genótipo (Quadro 2). Os valores do número de grãos por espiga obtidos por Oliveira et al. (1984) foram semelhantes, porém muito inferiores aos de Camargo et al. (1984), que empregaram plantas individuais em população segregante, e no trabalho presente, estudaram-se linhas puras (cultivares).

O número de grãos por espigueta praticamente não diferiu entre os genótipos IAC-60, IAC-24 e IAC5. Com relação às respostas ao calcário e/ou ao fósforo, de maneira geral, o IAC-60 teve as maiores respostas (Quadro 2).

A massa da matéria seca de cem grãos foi, de modo geral, a variável estudada mais afetada pelas aplicações de $\mathrm{P}$ quando não se aplicou calcário (Quadro 2). Na ausência de corretivos, os cultivares tolerantes ao alumínio tóxico (IAC-5, IAC-24 e IAC-60) apresentaram pouca ou nenhuma diferença entre si com relação à massa seca de grãos, ao passo que o 'Anahuac' mostrou grãos de menor massa. As diferenças entre os cultivares tendeu a desaparecer nas parcelas tratadas com calcário, nas quais todos os genótipos apresentaram massa de cem grãos em torno de 4,0 g (Quadro 2). 
O índice de colheita foi também afetado pela aplicação de calcário e de fósforo (Quadro 3). A adição de calcário promoveu maiores aumentos nos índices de colheita de todos os genótipos do que a de fósforo. Os valores apresentados pelos genótipos 'IAC-5' e 'IAC-60' (0,45 e 0,44 respectivamente) estão dentro da faixa mostrada por Austin et al. (1980) $(0,4$ a 0,5$)$. Nas parcelas tratadas com calcário, o 'IAC60' destacou-se, com valores do índice de colheita próximos a 0,5 . Os demais apresentaram dados relativamente mais baixos, refletindo as condições de crescimento em um solo de baixa fertilidade, no qual a produção de grãos foi proporcionalmente menor do que a de palha. Nas parcelas tratadas com 13 t.ha $^{-1}$ de calcário, os resultados obtidos com o 'Anahuac', de modo geral, foram semelhantes aos do 'IAC-5' e 'IAC-24', mas ainda inferiores aos do 'IAC60’ (Quadro 3).

O número de grãos por espiga teve o maior coeficiente médio de correlação linear $(0,86)$ com a produtividade dos grãos do trigo para as condições de sequeiro (Quadro 4), o que está de acordo com Evans et al. (1976) e Souza et al. (1996). Houve pequena variação entre os genótipos com relação a esse coeficiente $(0,80 ; 0,87 ; 0,88$ e 0,87 para 'IAC-5', 'IAC24', ' IAC-60' e 'Anahuac' respectivamente.

A produção de matéria seca da parte aérea e o número de grãos por espigueta ou índice de fertilidade foram o segundo e o terceiro componente que mais influenciaram a produtividade de grãos, com coeficientes de correlação linear de 0,83 e 0,82 respectivamente.

A produtividade de grãos também apresentou correlações relativamente altas com a altura de plantas, o comprimento de espiga e o número de espiguetas por espiga, mas um valor baixo $(0,46)$ para massa de cem grãos.

O índice de colheita mostrou baixa correlação com o rendimento de grãos e as demais características estudadas (Quadro 4). Isso provavelmente se deva à reduzida produção de grãos no tratamento sem a adição de calcário ou fósforo.

A população de plantas inicial (número de plantas por metro linear, antes do inicio do perfi- lhamento) mostrou pouca correlação com a produtividade de grãos e de matéria seca da parte aérea. A população de plantas no final (número de espiga por metro linear), no entanto, correlacionou-se relativamente melhor com o comprimento da espiga $(\mathrm{r}=0,52)$, número de espiguetas por espiga $(\mathrm{r}=54)$, matéria seca de 100 grãos $(r=0,64)$ e população inicial de plantas $(r=0,69)$.

Apesar das diferenças observadas entre cultivares em relação à produtividade de grãos em resposta à aplicação de fósforo e calcário, as variações nos valores dos coeficientes de correlação entre esta e seus componentes foram relativamente pequenas para os genótipos, sugerindo que os efeitos da fertilidade de solo sobre os componentes de produtividade são similares mesmo para genótipos com comportamento diferente em relação a exigências nutricionais, tais como 'Anahuac' e 'IAC-60'.

Os menores valores da produtividade de grãos, dos componentes desta e do comprimento da espiga, quando comparados com os de outros experimentos em solo com menor acidez e de fertilidade mais alta, sugere ser inviável produzir grãos utilizando-se cultivar com comportamento semelhante ao do 'Anahuac', em solo com acidez alta e fertilidade muito baixa, como o deste experimento (Freitas et al., 1994, 1995; Souza, 1996). Por outro lado, o desempenho dos cultivares IAC-5 e IAC-60 mostram que a tolerância ao alumínio e a eficiência no uso de fósforo e calcário podem contribuir para diminuir o custo de produção de grãos e viabilizar a produção de trigo em solos pobres.

\section{CONCLUSÕES}

1. Houve um efeito associativo positivo entre genótipos, calagem e fósforo aplicado.

2. Os genótipos de trigo 'IAC-60' e 'IAC-5' foram mais produtivos do que 'IAC-24' e 'Anahuac'.

3. A aplicação de calcário afetou mais o índice de colheita do que a adição de fósforo, enquanto 
a adubação fosfatada provocou maiores aumentos na produtividade de grãos do que a calagem.

4. O número de grãos por espiga foi o componente que melhor se correlacionou com a produtividade de grãos.

5. O uso de genótipos tolerantes à acidez, mais responsivos à aplicação de calcário e fósforo, pode ajudar a viabilizar a cultura de trigo em solos pobres, com menores investimentos.

\section{REFERÊNCIAS BIBLIOGRÁFICAS}

AUSTIN, R.B.; BINGHAM, J.; BLACKWELL, R.D.; EVANS, L.T.; FORD, M.A.; MORGAN, C.L. \& TAYLOR, M. Genetic improvements in winter wheat yield since 1900 and associated physiological changes. Journal of Agricultural Science, Cambridge, 94:675-689, 1980.

BATAGLIA, O.C.; CAMARGO, C.E.de O; OLIVEIRA, O.F. de; NAGAY, V. \& RAMOS, V.J. Resposta à calagem de três cultivares de trigo com tolerância diferencial ao alumínio. Revista Brasileira de Ciência do Solo, Campinas, 9(2):139-147, 1985.

BRASIL. Fundação Instituto Brasileiro de Geografia e Estatística (IBGE). Campinas, Capão Bonito. In: Enciclopédia dos municípios brasileiros. Rio de Janeiro, IBGE, 1957. v. 28, p.199 e 218.

CAMARGO, C.E.de O. Melhoramento do trigo. XX. Herdabilidade e coeficientes de correlação entre componentes de produção em populações híbridas envolvendo fontes de nanismo. Bragantia, Campinas, 48(1):39-52, 1989.

CAMARGO, C.E.de O. \& FELÍCIO, J.C. Trigo, triticale e centeio: avaliação da eficiência ao fósforo e tolerância à toxicidade ao alumínio. Bragantia, Campinas, 46(2): 203-215, 1987.

CAMARGO, C.E.de O.; FREITAS, J.G. \& CANTARELLA, H. Trigo. In: INSTITUTO AGRONÔMICO (Campinas). Recomendações de adubação e calagem para o Estado de São Paulo. 2.ed. Campinas, 1996. p. 68-71. (Boletim técnico, 100)

CAMARGO, C.E. de O. \& OLIVEIRA, O.F. Tolerância de cultivares de trigo a diferentes níveis de alumínio em solução nutritiva e no solo. Bragantia, Campinas, 40: 21-31, 1981.
CAMARGO, C.E.de O.; OLIVEIRA, O.F.; FERREIRA FILHO, A.W.P. \& CASTRO, J.L. de. Melhoramento do trigo: VII. Herdabilidade e coeficientes de correlação entre caracteres agronômicos em populações híbridas de trigo em diferentes solos paulistas. Bragantia, Campinas, 43(2): 293-312, 1984.

CLARK, R.B. Physiology of cereals for mineral nutrient uptake, use and efficiency. In: BALIGAR, V.C. \& DUNCAN, R.R. Crops as enhancers of nutrient use. New York, Academic Press, 1990. p.131-209.

COCHRAN, W.G. \& COX, G.M. Experimental designs. New York, Wiley Publications in Statistics, 1957. 618p.

EVANS, LT.; WARLAN, I.F. \& FISHER, R.A. Wheat. In: EVANS, LT. Crop physiology. London, Cambridge University Press, 1976. p.101-149.

FALCONER, D.S. Introdução à genética quantitativa. Viçosa, Imprensa Universitária da UFV, 1981. 279p.

FREITAS, J.G.; CAMARGO, C.E.de O.; FERREIRA FILHO, A.W.P. \& CASTRO, J.C. Eficiência e resposta de genótipos de trigo ao nitrogênio. Revista Brasileira de Ciência do Solo, Campinas, 19:229-234,1995.

FREITAS, J.G.; CAMARGO, C.E.de O.; FERREIRA FILHO, A.W.P. \& PETTINELli JÚNIOR, A. Produtividade e resposta de genótipos de trigo ao nitrogênio. Bragantia, Campinas, 53(2):281-290, 1994.

OLIVEIRA, O.F.; CAMARGO, C.E.de O. \& RAMOS, V. J. Efeito do fósforo sobre os componentes de produção, altura das plantas e rendimentos de grãos em trigo. Bragantia, Campinas, 43(1):31-44, 1984.

SILVA, A.R. da \& ANDRADE, J.M.V. de. Efeito de micronutrientes no chochamento do trigo de sequeiro e nas culturas da soja e arroz em Latossolo Vermelho-amarelo - fase arenosa. Pesquisa Agropecuária Brasileira, Brasília, 18(6):593-601, 1983.

SILVA, A.R.da; ANDRADE, J.M.V. de \& SANTOS, H.P. O chochamento do trigo e suas possíveis soluções. Ciência e Cultura, São Paulo, 32(1):72-78, 1980.

SOUZA, P.G.A. Resposta diferencial à calagem e ao fósforo de três cultivares de trigo (Triticum aestivum L.) com diferentes graus de tolerância ao alumínio. 137p. Jaboticabal, 1996. Tese (Doutorado) - Faculdade de Ciências Agrárias e Veterinárias/UNESP, 1996.

ZONTA, E.P.; MACHADO, A.A. \& SILVEIRA JUNIOR, P. Sistema de análise estatística para microcomputadores: manual de utilização. 2.ed. Pelotas, 1987. 177p. 